\title{
Effect of Temporal Bone Fracture on the Prognosis of Benign Paroxysmal Positional Vertigo
}

\author{
Munyoung Chang ${ }^{\mathbb{D}}$, Sei Young Lee ${ }^{\mathbb{D}}$, and Seog-Kyun Mun ${ }^{\mathbb{D}}$ \\ Department of Otorhinolaryngology-Head and Neck Surgery, Chung-Ang University College of Medicine, Seoul, Korea \\ 측두골 골절이 양성발작성두위현훈의 예후에 미치는 영향 \\ 장문영 · 이세영 · 문석균 \\ 중앙대학교 의과대학 이비인후과학교실
}

Received February 9, 2021

Revised February 19,2021

Accepted February 25, 2021

Address for correspondence

Seog-Kyun Mun, MD, PhD

Department of Otorhinolaryngology-

Head and Neck Surgery,

Chung-Ang University

College of Medicine,

102 Heukseok-ro, Dongjak-gu,

Seoul 06973, Korea

Tel $+82-2-6299-1765$

Fax $+82-2-825-1765$

E-mail entdoctor@cau.ac.kr
Background and Objectives This study aimed to investigate whether benign paroxysmal positional vertigo (BPPV) accompanied by temporal bone fracture would be more resistant to canalith repositioning procedures (CRPs) than idiopathic BPPV.

Subjects and Method Seventy-eight patients with BPPV were included in this study. Among them, 13 patients had temporal bone fractures and 65 had no temporal bone fractures. To identify the factors related to the number of CRPs performed until the remission of BPPV, sex, age, the presence of temporal bone fracture, hypertension, diabetes, dyslipidemia or osteopenia, BPPV affected side, and the type of affected semicircular canal were analyzed using the univariable regression analysis. Thereafter, the multivariable regression analysis was performed using only the variables that had a $p$-value of 0.2 or less in the univariable analysis. Results In the univariable analysis, temporal bone fracture, diabetes mellitus, and BPPV side showed relatively significant association with the number of CRPs $(p<0.2)$. In the multivariable analysis, only temporal bone fracture showed a significant association with the number of CRPs ( $p=0.043, \beta=0.532,95 \%$ CI: $0.017-1.046$ ).

Conclusion The major finding of this study is that BPPV, accompanied by temporal bone fracture, precipitated more resistance to CRPs than idiopathic BPPV did. Thus, patients with temporal bone fracture might need more intensive examination and treatment for BPPV than those without temporal bone fracture.

Korean J Otorhinolaryngol-Head Neck Surg 2021;64(12):868-73

Keywords Benign paroxysmal positional vertigo; Dizziness; Temporal bone.

\section{Introduction}

Benign paroxysmal positional vertigo (BPPV) is one of the most common diseases that can cause dizziness. Its prevalence is reported to be 11-64 per 100000 people, with a reported lifetime prevalence of $2.4 \%{ }^{1,2)}$ Although BPPV can be resolved with appropriate canalith repositioning procedures (CRPs),

This is an Open Access article distributed under the terms of the Creative Commons Attribution Non-Commercial License (https://creativecommons.org/licenses/by-nc/4.0) which permits unrestricted non-commercial use, distribution, and reproduction in any medium, provided the original work is properly cited.
BPPV also causes great mental stress in patients ${ }^{4,5)}$ and increases the risk of falling, ${ }^{6}$ further jeopardizing the health of the afflicted individual.

BPPV occurs when otoconia are detached from the otolithic organ and enter the semicircular canal (SCC). ${ }^{7-10)}$ Although it is suspected that otolith organ degeneration is the cause of otoconia detachment, the pathophysiology of this detachment is not clearly identified in most BPPV patients. ${ }^{11)}$ However, in some cases, the cause of otoconia detachment from the otolithic organ is readily apparent. For example, in case of BPPV 
occurring after head trauma, especially in patients with temporal bone fracture, the cause is relatively clear. Because the otolith organ is located within the temporal bone, it is subjected to a large external impact in the event of temporal bone fracture. As a result, this may destroy the filaments attaching the otoconia to the otolith organ. ${ }^{12)}$ Consequently, the otoconia may be detached from the otolith organ resulting in BPPV. Moreover, we believe that BPPV caused by temporal bone fracture would have greater damage to otolith organs relative to idiopathic BPPV. Accordingly, it was estimated that more otoconia would detach from the otolith organs, and that reattachment would be difficult after the CRPs. Therefore, we hypothesized that BPPV accompanied by temporal bone fracture would be more resistant to CRPs than idiopathic BPPV.

The incidence of BPPV in head trauma has been reported to be between $4.1 \%$ and $14.9 \%{ }^{13)}$ Therefore, the incidence of BPPV is also expected to be high after temporal bone fractures. Despite the expected high incidence, few studies have been done on BPPV accompanied by temporal bone fractures. ${ }^{14,15)}$ In this study, we aimed to investigate whether temporal bone fracture affects the number of CRPs performed for the remission of BPPV using univariable and multivariable regression analysis. The characteristics of BPPV accompanied by tempo- ral bone fractures can be identified and, ultimately, these data could contribute to the identification of BPPV pathophysiology.

\section{Subjects and Methods}

\section{Study design, population and study setting}

This study was conducted with the approval of Institutional Review Board of our hospital (IRB No. 1912-013-16292). This retrospective study included patients diagnosed with BPPV of the canalolithiasis type between January 2016 to December 2018, at our tertiary hospital. BPPV was diagnosed based on the presentation of typical whirling-type dizziness on positional changes and typical nystagmus during specific maneuvers, such as the Dix-Hallpike, and head-roll test identified by videonystagmography. Appropriate CRPs, such as Epley or barbecue rotation maneuvers, were conducted according to the affected SCC. ${ }^{16)}$ In a subsequent examination, the patient's symptoms and nystagmus were assessed, and if BPPV persisted, the appropriate CRP was performed. Otherwise, the CRP was not performed. The number of CRPs performed until the remission of BPPV was counted. To consistently estimate the number of CRPs, patients with an interval between CRPs for BPPV other than 3 or 4 days were excluded.
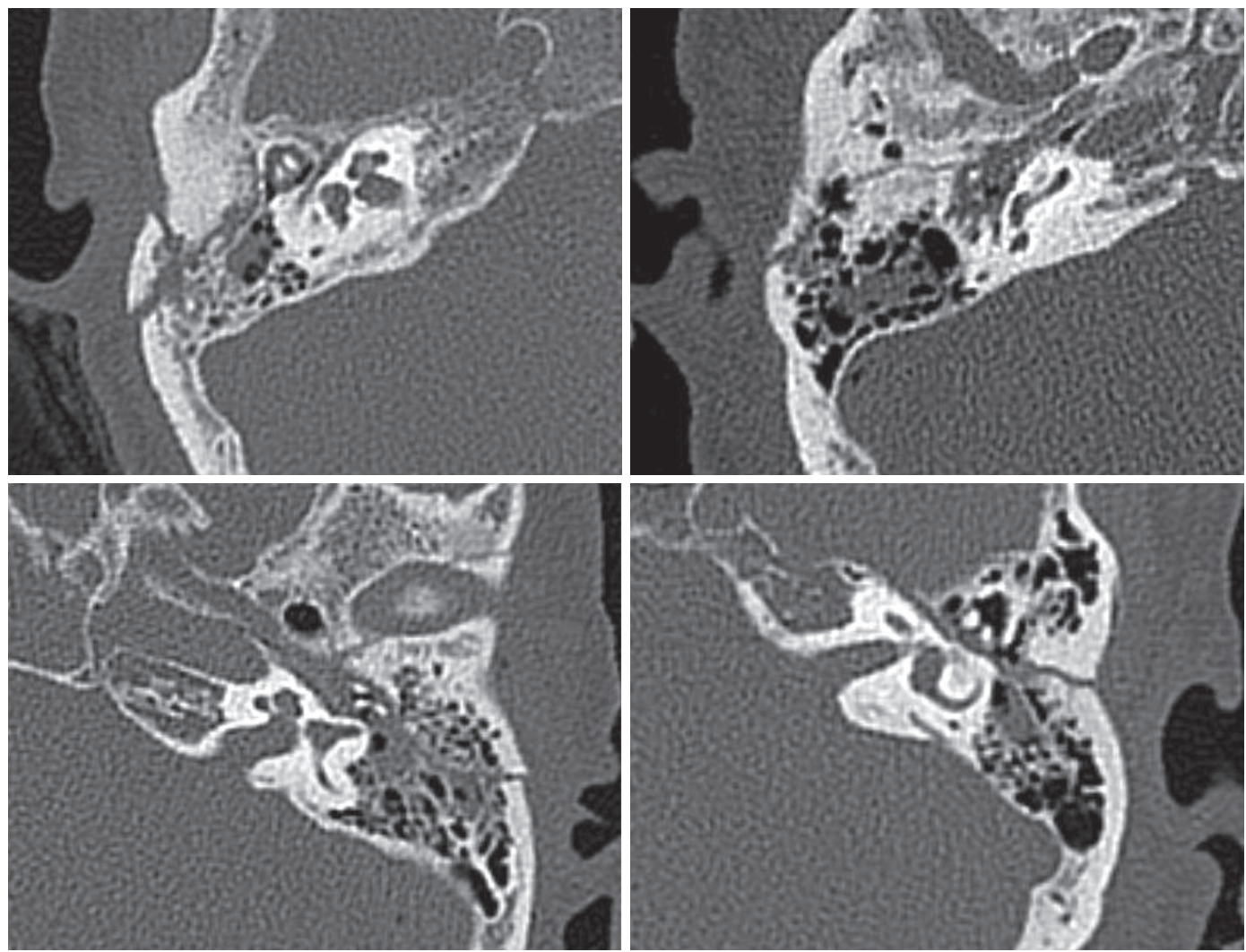

Fig. 1. The representative CT images of temporal bone fractures. 
The presence of temporal bone fracture was confirmed by temporal bone CT (Fig. 1). Among the patients with temporal bone fracture, patients with otic capsule-disrupting fracture were excluded. Among the patients without temporal bone fracture, patients with factors that could induce BPPV such as head trauma were excluded. Patients with multiple canal involvement or canal conversion during CRPs were excluded. Clinical features of the patients and information about BPPV were collected from their medical records.

\section{Statistical analysis}

Age, male and female sex ratios, number of CRPs performed for the remission of BPPV, prevalence of disease, and the side and type of the affected SCC were compared between patients with and without temporal bone fracture using the MannWhitney, Pearson chi-square or Fisher's exact test. To identify potential factors related to the number of CRPs, individual factors, including sex, age, the presence of temporal bone fracture, hypertension, diabetes, dyslipidemia or osteopenia, BPPV side, and the type of affected SCC were analyzed using univariable regression analysis. Then multivariable regression analysis was performed using only the variables with a $p$-value of 0.2 or less in the univariable analysis. Data were analyzed using SPSS (version 20.0; IBM Corp., Armonk, NY, USA) statistical software. Statistical significance was determined by a $p$-value $<0.05$.

\section{Results}

A total of 78 patients were included in this study. Among them, 13 had temporal bone fractures and 65 had no temporal bone fractures. The clinical characteristics of the included patients are summarized in Table 1. The mean age of patients, without and with temporal bone fractures, was $53.1( \pm 14.0)$ years and $50.1( \pm 21.9)$ years, respectively, without any significant difference between the two groups $(p=0.788)$. The mean number of CRPs performed for the remission of BPPV in patients with temporal bone fracture was $2.7( \pm 1.2)$, which was larger than that in patients without temporal bone fracture of $2.1( \pm 0.8)$ (Fig. 2). This difference was significant ( $p=0.045$ ). There was no significant difference in the sex ratios, prevalence of hypertension, diabetes mellitus, dyslipidemia or osteopenia, BPPV side, and type of the affected SCC between the two groups $(p>0.05)$.

The result of univariable analysis showed that temporal bone fracture ( $p=0.017, \beta=0.631,95 \% \mathrm{CI}: 0.118-1.143)$, dia- betes mellitus ( $p=0.065, \beta=0.433,95 \% \mathrm{CI}:-0.027-0.894$ ), and BPPV side ( $p=0.182, \beta=-0.266,95 \%$ CI: $-0.658-0.127)$ showed a relatively significant association with the number of CRPs $(p<0.2)$ (Table 2). Multivariable analysis was performed with variables having a $p$-value of less than 0.2 in the univariable analysis. Only temporal bone fracture showed a significant association with the number of CRPs $(p=0.043, \beta=0.532,95 \%$ CI: 0.017-1.046). The BPPV side and diabetes mellitus showed no statistical significance with the number of CRPs (Table 3).

Table 1. Demographics of the study population

\begin{tabular}{|c|c|c|c|}
\hline Characteristic & Total & $\begin{array}{l}\text { Temporal } \\
\text { bone } \\
\text { fracture (-) }\end{array}$ & $\begin{array}{c}\text { Temporal } \\
\text { bone } \\
\text { fracture }(+)\end{array}$ \\
\hline \multicolumn{4}{|l|}{ Age (years) } \\
\hline $10-19$ & $3(3.8)$ & $2(3.1)$ & $1(7.7)$ \\
\hline $20-29$ & $3(3.8)$ & $1(1.5)$ & $2(15.4)$ \\
\hline $30-49$ & $12(15.4)$ & $10(15.4)$ & $2(15.4)$ \\
\hline $40-49$ & $11(14.1)$ & $10(15.4)$ & $1(7.7)$ \\
\hline $50-59$ & $21(26.9)$ & $19(29.2)$ & $2(15.4)$ \\
\hline $60-69$ & $19(24.4)$ & $17(26.2)$ & $2(15.4)$ \\
\hline $70-79$ & $8(10.3)$ & $6(9.2)$ & $2(15.4)$ \\
\hline $80-89$ & $1(1.3)$ & $0(0.0)$ & $1(7.7)$ \\
\hline Mean & $52.6( \pm 15.5)$ & $53.1( \pm 14.0)$ & $50.1( \pm 21.9)$ \\
\hline \multicolumn{4}{|l|}{ Sex } \\
\hline Male & $24(30.8)$ & $17(26.2)$ & $7(53.8)$ \\
\hline Female & $54(69.2)$ & $48(73.8)$ & $6(46.2)$ \\
\hline $\begin{array}{l}\text { Number of canalith } \\
\text { repositioning }\end{array}$ & $2.2( \pm 0.9)$ & $2.1( \pm 0.8)$ & $2.7( \pm 1.2)$ \\
\hline procedure $( \pm S D)$ & & & \\
\hline \multicolumn{4}{|l|}{ Hypertension } \\
\hline Yes & $25(32.1)$ & $22(33.8)$ & $3(23.1)$ \\
\hline No & $53(67.9)$ & $43(66.2)$ & $10(76.9)$ \\
\hline \multicolumn{4}{|l|}{ Diabetes mellitus } \\
\hline Yes & $18(23.1)$ & $13(20.0)$ & $5(38.5)$ \\
\hline No & $60(76.9)$ & $52(80.0)$ & $8(61.5)$ \\
\hline \multicolumn{4}{|l|}{ Dyslipidemia } \\
\hline Yes & $11(14.1)$ & $10(15.4)$ & $1(7.7)$ \\
\hline No & $67(85.9)$ & $55(84.6)$ & $12(92.3)$ \\
\hline \multicolumn{4}{|l|}{ Osteopenia } \\
\hline Yes & $8(10.3)$ & $7(10.8)$ & $1(7.7)$ \\
\hline No & $70(89.7)$ & $58(89.2)$ & $12(92.3)$ \\
\hline \multicolumn{4}{|l|}{ BPPV side } \\
\hline Right & $41(52.6)$ & $33(50.8)$ & $8(61.5)$ \\
\hline Left & $37(47.4)$ & $32(49.2)$ & $5(38.5)$ \\
\hline \multicolumn{4}{|l|}{ Affected canal } \\
\hline Posterior & $56(71.8)$ & $47(72.3)$ & $9(69.2)$ \\
\hline Lateral & $22(28.2)$ & $18(27.7)$ & $4(30.8)$ \\
\hline
\end{tabular}




\section{Discussion}

The pathophysiology underlying otoconia detachment in most BPPV cases is unknown, and external shock/traumas, such as temporal bone fractures are estimated to influence the prognosis of BPPV. Therefore, based on the hypothesis that BPPV associated with temporal bone fracture would be more resistant to CRPs, this study retrospectively investigated the factors associated with the number of CRPs performed for the remission of BPPV in patients with and without temporal bone fractures.

According to the results of this study, the mean number of CRPs performed in patients with temporal bone fracture was 2.7, which was larger than that in patients without temporal bone fracture (2.1). The results of multivariable analysis also revealed that BPPV accompanied by temporal bone fracture requires more frequent CRPs than idiopathic BPPV. This finding is similar to that reported in previous studies, which stated that BPPV caused by trauma has a lower treatment success rate than idiopathic BPPV. ${ }^{14,15)}$ This interaction is presumed to be a result of compounded damage to the otolith organs in the case of BPPV accompanied by temporal bone fracture. If the otolith organs were severely damaged, the structures supporting the otoconia in the otolith organ might be destroyed. ${ }^{12)}$ Even after the successful CRPs, the otoconia might detach from the otolith organs again, leading to persistence of BPPV.

Since the otoconia causing BPPV originates from the otolith organ, the state of the otolith organ should be considered

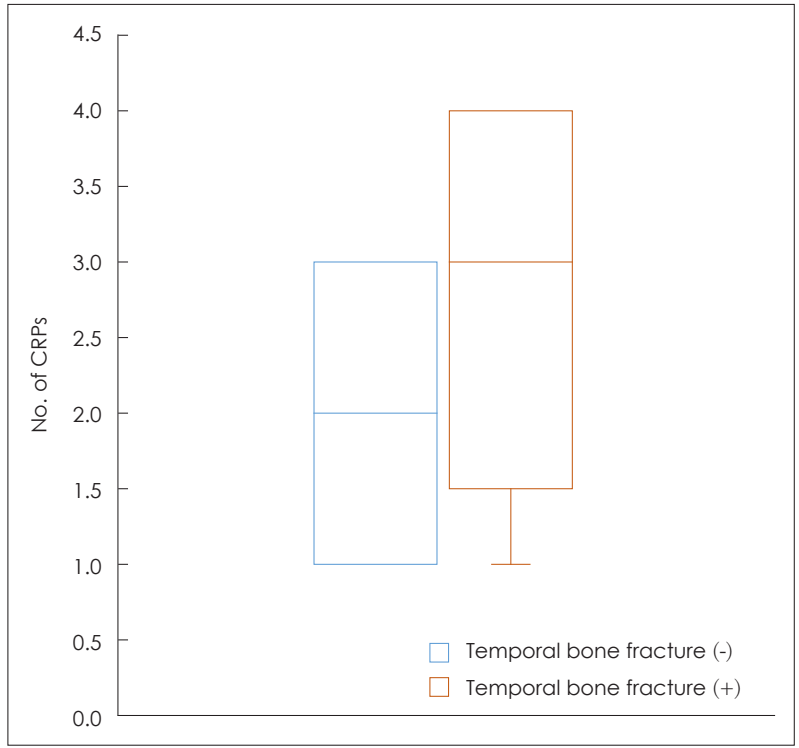

Fig. 2. The number of CRPs performed until the remission of benign paroxysmal positional vertigo in the patients with or without temporal bone fracture. CRP, canalith repositioning procedure. when predicting the prognosis of BPPV. Several studies have evaluated the state of otolith organs using cervical/ocular vestibular evoked myogenic potential (c/oVEMP). Based on these results, they have reported the association between the state of otolith organs and BPPV. ${ }^{8,17-23)}$ These studies compared

Table 2. Univariable regression analysis of factors potentially associated with the number of canalith repositioning procedures performed

\begin{tabular}{|c|c|c|c|}
\hline & $p$-value & $\beta$ & $95 \% \mathrm{Cl}$ \\
\hline \multicolumn{4}{|l|}{ Sex } \\
\hline Male & \multicolumn{3}{|c|}{ Reference } \\
\hline Female & 0.403 & -0.181 & $-0.608-0.247$ \\
\hline Age & 0.748 & 0.002 & $-0.011-0.015$ \\
\hline \multicolumn{4}{|c|}{ Temporal bone fracture } \\
\hline No & \multicolumn{3}{|c|}{ Reference } \\
\hline Yes & 0.017 & 0.631 & $0.118-1.143$ \\
\hline \multicolumn{4}{|l|}{ Hypertension } \\
\hline No & \multicolumn{3}{|c|}{ Reference } \\
\hline Yes & 0.819 & 0.049 & $-0.376-0.474$ \\
\hline \multicolumn{4}{|l|}{ Diabetes mellitus } \\
\hline No & \multicolumn{3}{|c|}{ Reference } \\
\hline Yes & 0.065 & 0.433 & $-0.027-0.894$ \\
\hline \multicolumn{4}{|l|}{ Dyslipidemia } \\
\hline No & \multicolumn{3}{|c|}{ Reference } \\
\hline Yes & 0.295 & -0.300 & $-0.866-0.266$ \\
\hline \multicolumn{4}{|c|}{ Osteoporosis or osteopenia } \\
\hline No & \multicolumn{3}{|c|}{ Reference } \\
\hline Yes & 0.888 & -0.046 & $-0.700-0.607$ \\
\hline \multicolumn{4}{|l|}{ BPPV side } \\
\hline Right & \multicolumn{3}{|c|}{ Reference } \\
\hline Left & 0.182 & -0.266 & $-0.658-0.127$ \\
\hline \multicolumn{4}{|l|}{ Affected SCC } \\
\hline Posterior canal & \multicolumn{3}{|c|}{ Reference } \\
\hline Lateral canal & 0.294 & -0.232 & $-0.670-0.206$ \\
\hline
\end{tabular}

Table 3. Multivariate regression analysis of factors associated with the number of canalith repositioning procedures performed

\begin{tabular}{|c|c|c|c|}
\hline & p-value & $\beta$ & $95 \% \mathrm{Cl}$ \\
\hline \multicolumn{4}{|c|}{ Temporal bone fracture } \\
\hline No & \multicolumn{3}{|c|}{ Reference } \\
\hline Yes & 0.043 & 0.532 & $0.017-1.046$ \\
\hline \multicolumn{4}{|c|}{ Diabetes mellitus } \\
\hline No & \multicolumn{3}{|c|}{ Reference } \\
\hline Yes & 0.097 & 0.384 & $-0.071-0.840$ \\
\hline \multicolumn{4}{|c|}{ BPPV side } \\
\hline Right & \multicolumn{3}{|c|}{ Reference } \\
\hline Left & 0.173 & -0.263 & $-0.643-0.118$ \\
\hline
\end{tabular}

$\mathrm{Cl}$, confidence interval; BPPV, benign paroxysmal positional vertigo 
c/oVEMP results between BPPV patients and normal subjects, or between affected and unaffected sides in BPPV patients. As a result, it was reported that abnormal results of c/oVEMP were more commonly measured in BPPV patients or on the affected side. ${ }^{8,17,20-23)}$ Furthermore, some studies have predicted the prognosis of BPPV based on the state of the otolith organs using c/oVEMP. ${ }^{19,20,23)}$ Lee, et al. ${ }^{19)}$ and $\mathrm{Xu}$, et al. ${ }^{23)}$ reported that c/oVEMP response was more often absent in the recurrent BPPV patients. Longo, et al. ${ }^{20)}$ reported the association between the results of cVEMP and number of BPPV attacks. In our previous study using cVEMP, it was confirmed that BPPV showed resistance to CRPs in the presence of abnormalities in the otolith organ. ${ }^{11)}$ Consequently, severe damage to the otolith organs due to temporal bone fracture is expected to be associated with resistance to CRPs.

In order to consider the number of CRPs performed until the remission of BPPV as resistance to treatment, the interval between CRPs must be constant. As our hospital treats most BPPV patients every 3 to 4 days, the interval between CRPs for BPPV is mostly 3 or 4 days. To keep this more strictly, patients with an interval between CRPs for BPPV other than 3 or 4 days were excluded.

This study has limitations. First, we assumed that patients with BPPV accompanied by temporal bone fracture had more severe damage to the otolith organs. However, the condition of otolith organs was not directly measured. In follow-up studies, it would be helpful to measure the condition of otolith organs in BPPV patients with temporal bone fracture and idiopathic BPPV patients using c/oVEMP. Second, the number of patients with temporal bone fracture included in the study is not large. Future studies will include more patients to obtain more robust results.

In conclusion, this study revealed that BPPV accompanied by temporal bone fracture, inflicting significant damage to the otolith organ, may be more resistant to CRPs than idiopathic BPPV. Therefore, patients with temporal bone fracture warrant more intensive examination and treatment of BPPV than those without temporal bone fracture. In addition, this study contributed to clarifying the pathophysiology underlying the development of BPPV.

\section{Acknowledgments}

None.

\section{Author Contribution}

Conceptualization: all authors. Data curation: Munyoung Chang. Formal analysis: Munyoung Chang, Seog-Kyun Mun. Methodology:
Munyoung Chang. Project administration: Munyoung Chang, SeogKyun Mun. Visualization: Munyoung Chang, Seog-Kyun Mun. Writing - original draft: Munyoung Chang. Writing - review \& editing: Sei Young Lee, Seog-Kyun Mun.

\section{ORCIDs}

Seog-Kyun Mun https://orcid.org/0000-0001-8624-2964

Munyoung Chang https://orcid.org/0000-0003-0136-3893

Sei Young Lee https://orcid.org/0000-0001-6034-6386

\section{REFERENCES}

1) Bhattacharyya N, Baugh RF, Orvidas L, Barrs D, Bronston LJ, Cass S, et al. Clinical practice guideline: Benign paroxysmal positional vertigo. Otolaryngol Head Neck Surg 2008;139(5 Suppl 4): S47-81.

2) von Brevern M, Radtke A, Lezius F, Feldmann M, Ziese T, Lempert T, et al. Epidemiology of benign paroxysmal positional vertigo: A population based study. J Neurol Neurosurg Psychiatry 2007;78(7):710-5.

3) Baloh RW, Honrubia V, Jacobson K. Benign positional vertigo: Clinical and oculographic features in 240 cases. Neurology 1987; 37(3):371-8.

4) Park MK, Lee DY, Kim YH. Risk factors for positional vertigo and the impact of vertigo on daily life: The Korean national health and nutrition examination survey. J Audiol Otol 2019;23(1):8-14.

5) Roberts RA, Abrams H, Sembach MK, Lister JJ, Gans RE, Chisolm TH. Utility measures of health-related quality of life in patients treated for benign paroxysmal positional vertigo. Ear Hear 2009; 30(3):369-76.

6) Lopez-Escamez JA, Gamiz MJ, Fernandez-Perez A, Gomez-Fiñana M. Long-term outcome and health-related quality of life in benign paroxysmal positional vertigo. Eur Arch Otorhinolaryngol 2005; 262(6):507-11.

7) Gacek RR. Pathology of benign paroxysmal positional vertigo revisited. Ann Otol Rhinol Laryngol 2003;112(7):574-82.

8) Korres S, Gkoritsa E, Giannakakou-Razelou D, Yiotakis I, Riga M, Nikolpoulos TP. Vestibular evoked myogenic potentials in patients with BPPV. Med Sci Monit 2011;17(1):CR42-7.

9) Welling DB, Parnes LS, O’Brien B, Bakaletz LO, Brackmann DE, Hinojosa R. Particulate matter in the posterior semicircular canal. Laryngoscope 1997;107(1):90-4.

10) Zappia JJ. Benign paroxysmal positional vertigo. Curr Opin Otolaryngol Head Neck Surg 2013;21(5):480-6.

11) Chang MY, Shin JH, Oh KH, Hong YH, Mun SK. Clinical implication of cervical vestibular evoked myogenic potentials in benign paroxysmal positional vertigo. Clin Neurophysiol 2017; 128(2):351-6.

12) Lins U, Farina M, Kurc M, Riordan G, Thalmann R, Thalmann I, et al. The otoconia of the guinea pig utricle: Internal structure, surface exposure, and interactions with the filament matrix. J Struct Biol 2000;131(1):67-78.

13) Balatsouras DG, Koukoutsis G, Aspris A, Fassolis A, Moukos A, Economou NC, et al. Benign paroxysmal positional vertigo secondary to mild head trauma. Ann Otol Rhinol Laryngol 2017; 126(1):54-60.

14) Pisani V, Mazzone S, Di Mauro R, Giacomini PG, Di Girolamo S. A survey of the nature of trauma of post-traumatic benign paroxysmal positional vertigo. Int J Audiol 2015;54(5):329-33.

15) Liu H. Presentation and outcome of post-traumatic benign paroxysmal positional vertigo. Acta Otolaryngol 2012;132(8):803-6.

16) Kim JS, Zee DS. Clinical practice. Benign paroxysmal positional vertigo. N Engl J Med 2014;370(12):1138-47. 
17) Hong SM, Park DC, Yeo SG, Cha CI. Vestibular evoked myogenic potentials in patients with benign paroxysmal positional vertigo involving each semicircular canal. Am J Otolaryngol 2008;29(3): 184-7.

18) Hoseinabadi R, Pourbakht A, Yazdani N, Kouhi A, Kamali M. The effects of abnormality of cVEMP and oVEMP on rehabilitation outcomes in patients with idiopathic benign paroxysmal positional vertigo. Eur Arch Otorhinolaryngol 2016;273(3):643-8.

19) Lee JD, Park MK, Lee BD, Lee TK, Sung KB, Park JY. Abnormality of cervical vestibular-evoked myogenic potentials and ocular vestibular-evoked myogenic potentials in patients with recurrent benign paroxysmal postitional vertigo. Acta Otolaryngol 2013; 133(2):150-3.

20) Longo G, Onofri M, Pellicciari T, Quaranta N. Benign paroxysmal positional vertigo: Is vestibular evoked myogenic potential testing useful? Acta Otolaryngol 2012;132(1):39-43.

21) Singh NK, Apeksha K. Efficacy of cervical and ocular vestibularevoked myogenic potentials in evaluation of benign paroxysmal positional vertigo of posterior semicircular canal. Eur Arch Otorhinolaryngol 2016;273(9):2523-32.

22) Sreenivasan A, Sivaraman G, Parida PK, Alexander A, Saxena SK, Suria G. The clinical utility of vestibular evoked myogenic potentials in patients of benign paroxysmal positional vertigo. J Clin Diagn Res 2015;9(6):MC01-3.

23) $\mathrm{Xu} \mathrm{H}$, Liang FY, Chen L, Song XC, Tong MC, Thong JF, et al. Evaluation of the utricular and saccular function using oVEMPs and cVEMPs in BPPV patients. J Otolaryngol Head Neck Surg 2016;45:12. 